\title{
LA PROTECCIÓN DEL CRÉDITO TRANSFRONTERIZO MEDIANTE LA ORDEN EUROPEA DE RETENCIÓN DE CUENTAS. EN TORNO A LA STJUE C-555/18 DE 7 DE NOVIEMBRE DE 2019
}

\author{
THE PROTECTION OF THE CROSS-BORDER CREDIT BY THE \\ EUROPEAN ACCOUNT PRESERVATION ORDER. REGARDING \\ THE ECJ JUDGMENT C-555/18 OF 7 NOVEMBER OF 2019
}

\author{
ISABEL ANTÓN JuÁREZ \\ Profesora titular acr. de Derecho Internacional privado \\ Universidad Carlos III de Madrid \\ ORCID ID: 0000-0002-5369-2301
}

Recibido: 14.12.2019 / Aceptado: 10.01.2020

DOI: https://doi.org/10.20318/cdt.2020.5197

\begin{abstract}
Resumen: La orden europea de retención de cuentas es una medida muy útil que intenta facilitar el cobro de las deudas transfronterizas. La sentencia del TJUE de 7 de noviembre de 2019 es la primera sentencia sobre el Reglamento 655/2014. Reglamento europeo que instaura esta medida cautelar europea en todos los Estados miembros de la UE a excepción de Dinamarca. Esta sentencia muestra que la aplicación de la orden europea de retención de cuentas puede no resultar fácil de aplicar a los tribunales nacionales. Una de las razones es que su aplicación requiere de una combinación armónica entre lo dispuesto en el Reglamento 655/2014 y los derechos procesales nacionales. El TJUE, con esta sentencia que analizamos, intenta allanar el camino hacia la búsqueda de esa aplicación armónica y sobre todo homogénea del R. 655/2014 por los tribunales nacionales de los Estados miembros.
\end{abstract}

Palabras clave: medida cautelar, orden europea de retención de cuentas, deuda transfronteriza.

Abstract: The European Account Preservation Order is a very useful measure that attempts to facilite the collection of cross-border debts. The ECJ judgment of 7 of November of 2019 is the first about the Regulation 655/2014. This Regulation establishes the European precautionary measure in all EU member states with the exception of Denmark. This ruling shows that the application of the European Account Preservation Order may not be easy to apply to national courts. One of the reasons is that its application requires a harmonious combination between the provisions of Regulation 655/2014 and national procedural orders. The ECJ with this judgment that we analyze tries to pave the way towards the search for that harmonious and especially homogeneous application of R. 655/2014 by the national courts of the member states.

Keywords: provisional measure, European Account Preservation Order, cross-border debt.

Sumario: I. Introducción. II. Razones que influyen en la dificultad del cobro de una deuda transfronteriza. III. Pero, ¿Qué es una Orden Europea de Retención de Cuentas?.IV. Problemas jurídicos que suscita esta resolución. 1.La importancia de si el acreedor tiene reconocido o no su crédito mediante una resolución judicial, transacción judicial o documento público con fuerza ejecutiva. A) Aproximación al problema. B) La solución del TJUE. 2.La amplitud del concepto "procedimiento en cuanto al fondo" del art. 5 letra a R. 655/2014. 3. En torno a qué engloba el término "circunstancias excepcionales" del art. 45 R. 655/2014. V. Reflexiones finales. 


\section{Introducción}

1. El objeto del presente trabajo es el estudio de la STJUE de 7 de noviembre de $2019^{1}$. Esta sentencia es la primera que dicta el Tribunal de Justicia ${ }^{2}$ en relación al Reglamento (UE) $N^{o} 655 / 2014$ del Parlamento Europeo y del Consejo de 15 de mayo de 2014 por el que se establece el procedimiento relativo a la orden europea de retención de cuentas a fin de simplificar el cobro transfronterizo de deudas en materia civil y mercantil (en adelante, R. 655/2014) 3 $^{3}$ De este modo, en primer lugar, haremos una breve aproximación sobre qué es la OERC para luego pasar a analizar los problemas jurídicos que suscita este asunto. Así, en particular, vamos a destacar uno y es en relación a la diferencia de tratamiento que existe en R. 655/2014 para solicitar y resolver sobre la OERC cuando se dispone de una resolución judicial, transacción judicial o documento público con fuerza ejecutiva que en el caso de que se disponga de un título que reconozca la deuda. IV. Hechos litigiosos de la STJUE de 7 de noviembre de 2019.

\section{Razones que influyen en la dificultad del cobro de una deuda transfronteriza}

2. Las relaciones comerciales internacionales son muy frecuentes. Esto es una obviedad hoy en día. Sin embargo, lo que no resulta tan obvio, o al menos mucho menos conocido, es la dificultad que entraña el cobro de una deuda transfronteriza. Es decir, esa deuda que se ostenta contra una persona, bien física o jurídica, que tiene sus fondos en uno o varios países distintos de donde reside el acreedor.

Con el fin de proteger el crédito transfronterizo se crea la orden europea de retención de cuentas (en adelante, la OERC) ${ }^{4}$. Esta medida cautelar europea se instaura a través del citado R. 655/2014.

\footnotetext{
${ }^{1}$ STJUE 7 de noviembre 2019, K.H.K contra B.A.C. Y E.E.K, C-555/18, ECLI:EU:C:2019:937.

${ }^{2}$ Conclusiones del Abogado general Sr. Maciej SzPunar presentadas el 29 de julio de 2019, ECLI: EU:C:2019:652.

${ }^{3}$ DOUE L 189/59 de 27 de junio de 2014.
}

4 Sobre la OERC en la doctrina nacional vid. I. ANTÓN JuÁREZ, Litigación Internacional en la Unión Europea. La Orden Europea de Retención de Cuentas, Thomson Reuters Aranzadi, Navarra, 2018; ID., "La orden Europea de retención de cuentas: ¿Adiós a la dificultad que plantea el cobro de la deuda transfronteriza en la UE?", CDT, Vol. 9, № 1, pp. 5-48; F. Cordón Moreno, "La orden europea de retención de cuentas en un proceso seguido en España: ¿Naturaleza cautelar o ejecutiva?, REDI, vol.69/2, juliodiciembre 2017, pp. 301-308;L. Domínguez Ruiz, Reclamación de Deudas Transfronterizas, Thomson Reuters Aranzadi, Cizur Menor (Navarra), 2013, pp. 257- 275; P. JIMÉNEZ BLANCO, "La orden europea de retención de cuentas: avances y limitaciones", AEDIPriv, t-XIV-XV,2014-2015, pp. 243-275;M. FonT I MAS, "El Reglamento 655/2014 del Parlamento Europeo y del Consejo de 15 de mayo de 2014 por el que se establece el procedimiento relativo a la orden europea de retención de cuentas a fin de simplificar el cobro transfronterizo de deudas en materia civil y mercantil", REDI, vol, 67 (2015), pp. 329-334;;I. LóPEz ChOCARRo, "La orden Europea de retención de cuentas bancarias; breve análisis del Reglamento (UE) № 655/2014 del Parlamento Europeo ante su inmediata aplicación a partir del día 18 de enero de 2017”, Diario La Ley, № 8903, Sección Tribuna, 18 de Enero de 2017;F. Martin Diz, "La orden europea de embargo de activos bancarios", en C. Aranguena Fanego (Coord.), Cooperación judicial civil y penal en el nuevo escenario de Lisboa, Comares, Granada, 2011, pp. 133-147;P. DE Miguel Asensio, "Aplicación de la orden europea de retención de cuentas", Blog, entrada de 16 de enero de 2017. Disponible en http://pedrodemiguelasensio.blogspot. com.es/2017/01/aplicacion-de-la-orden-europea-de.html;R. Miquel SALA, "La futura orden europea de retención de cuentas para simplificar el cobro transfronterizo de deudas en materia civil y mercantil”, Cuadernos de Derecho Transnacional(CDT), vol. 4, $\mathrm{n}^{\circ}$ 2, pp. 217-247; Ma . Ángeles Rodríguez VÁzquez, "La orden europea de retención de cuentas", Revista de Derecho Patrimonial, 38, 2015, pp. 145-160;C. SeNÉs MotiLla, "La orden europea de retención de cuentas: una apuesta decidida por la tutela cautelar del crédito en asuntos transfronterizos, REDI, vol.69/2, julio-diciembre 2017, pp. 309-316;C. SenÉs Motilla, La orden Europea de Retención de Cuentas. Aplicación en Derecho español del Reglamento (UE) núm. 655/2014, de 15 de mayo de 2014, Thomson Reuters Aranzadi, Cizur Menor (Navarra), 2015;M.T. Solís SANTOS,"Chapter 5. Cross border creditor's protection: the impact of the european account preservation order", en J.-S. BERGÉ/S. FRANQ/S.M. GARDEÑÉs, Boundaries of European Private International Law, Bruylant, 2015, pp. 199-210; D. Vilas Álvarez, El Reglamento por el que se crea una Orden Europea de Retención y Mercantiles: claves de su elaboración, La Ley mercantil, $n^{\circ} 6,2014$, pp. 1-14. En la doctrina extranjera, vid, En la doctrina extranjera, vid. E. D'Alessandro, <<I mezzi di ricorso e la protezione dei terzi >>, en P. Franzina/A. Leandro, Ilsequestro europeo di contibancari. Regolamento (UE) n. 655/2014 de 15 maggio 2014, Giuffrèeditore, Milán, 2015 pp. 87-117;G. CUNIBERTI/S. MigLIORINI, The European Account Preservation Order Regulation. A commentary, Cambridge, 2018;E. DE Götzen, "Cobro transfronterizo de deudas en materia civil y mercantil: ¿Dónde estamos y hacia dónde nos dirigimos?”, AEDIPr, t. XIII, 2013, pp. 309-340;A. DICKINson, "Provisional measures in the 'Brussels I' Review: disturbing the Status Quo?", J. Priv. Int'L., vol.6, no 3, 2010, pp. 519 y ss;L. Domínguez Ruz, "La orden europea de retención de cuentas", Revista de Derecho Civil, Vol. 1, no 4 (octubre-diciembre 2014), pp. 243-256; P. Franzina/A. LeAndro, Il sequestro europeo di conti bancari. Regolamento (UE) n. 655/2014 de 15 maggio 2014 , Giuffrè editore, Milán, 2015;A. v. FALCK, Implementierung offener ausländischer Vollstreckungstitel. Vollstreckbarerklärung ausländischer Titel und inländischer Bestimmtheitsgrundsatz, Gieseking, E.U.W. Gmbh, 1998; J. von HeIN, <<European Account 
Como posteriormente analizaremos, es una medida que persigue evitar que el deudor enajene parte de su patrimonio cuando existe un procedimiento de reclamación de deuda contra él. Con el fin de facilitar su interposición al acreedor y crear un procedimiento lo más homogéneo posible, su solicitud al igual que su resolución o ejecución se deben realizar mediante los formularios previstos en el Reglamento de Ejecución (UE) 2016/1823 de la Comisión de 10 de octubre de 2016 por el que se establecen los formularios mencionados en el Reglamento (UE) $N^{o}$ 655/2014 del Parlamento Europeo y del Consejo por el que se establece el procedimiento relativo a la orden europea de retención de cuentas a fin de simplificar el cobro transfronterizo de deudas en materia civil y mercantil ${ }^{5}$.

3. Una medida como la OERC es actualmente más que necesaria debido a la dificultad que entraña la ejecución de las resoluciones judiciales. Varias son las razones que sustentan la afirmación anterior:

1) El lapso de tiempo entre la resolución y su posterior ejecución $n^{6}$. Los procedimientos internacionales no se caracterizan por su rapidez precisamente. Esto da lugar a que el patrimonio del deudor pueda disminuir, ya no sólo por enajenaciones que el propio deudor realice sino también porque puede que existan otros acreedores que tengan derecho a cobrar su crédito;

2) El diferente tratamiento entre Estados miembros de la tutela cautelar transfronteriza. Los tribunales estatales sólo tienen poder de ejecutar en el territorio donde ejercen su función jurisdiccional. Así, cuando se reclama una deuda transfronteriza, el escenario habitual es que se puede desarrollar el litigio en el Estado A pero en realidad los fondos del deudor se encuentran en el Estado B. Con el fin de evitar la situación de que al acabar el litigio no quede patrimonio del deudor que ejecutar, es necesario solicitar una medida cautelar transfronteriza. Sin embargo, esta cuestión no ha sido regulada a nivel internacional ni tampoco de forma demasiado efectiva a nivel europeo. En relación a este último ámbito es necesario acudir al Reglamento 1215/2012 del Parlamento Europeo y del Consejo de 12 de octubre

Preservation Order Regulation (capitulo E.14)>>, en J. BASEDOw/ G. RÜHL/ F.FerRARI/P.M. AsEnsio, Encyclopedia of Private International Law, Edwgar Elgar Publishing,2017, pp. 681-687;B. Hess, Study No. JAI/A3/2002/02, on making more efficient the enforcement of judicial decisions within the European Union:Transparency of a Debtor's Assets Attachment of Bank Accounts Provisional Enforcement and Protective Measures (Version of 2/18/2004);B.Hess/ K. RAFFELSIEPER, "Eckpunkte der Kontenpfändungsverordnung", en B. Hess, Die Anerkennung im Internationalen Zivilprozessrecht - Europäisches Vollstreckungsrecht, Band 21, Gieseking-Verlag,Bielefeld, 2014, pp. 214-222; N.KYRIAKIDES, "The United Kingdom's Stance to the Recently Introduced European Account Preservation Order,C.J.Q, 33, 4, 2014, pp. 375-378;N.KYRIAKIDES, "Chapter 4.European account preservation order: What does the common law tradition have to say", en J.-S. Bergé/S. FranQ/M. Gardeñés Santiago, Boundaries of European Private International Law, Bruylant, 2015, pp. 189-198;A. LEANDRo, "Arbitration and European Account preservation Order", 2016, http://arbitrationblog.kluwerarbitration.com/2016/04/04/arbitration-european-account-preservation-order/;A. LEANDRO, "La circolazione dell' ordinanza europea di sequestroc conservativo dei conti bancari", en P. FrANZINA/A. LeANDro, Ilsequestro europeo di contibancari. Regolamento (UE) n. 655/2014 de 15 maggio 2014, Giuffrèeditore, Milán, 2015, pp. 119-145;E. Lew, "Speedy cross-border debt recovery? The new Europe-wide feezing order", Butterworths Journal of International and Financial Law, December 2011, pp- 609-701n de cuentas: avances y limitaciones" ,AEDIPr, t. XIV-XV, 2014-2015, pp. 243-275; MAX PLANCK WorKING Group, Comments on the European Comission's green paper on improving the efficiency of the enforcement of judgments in the European Union: the attachment of bank accounts, Disponible en http://ec.europa.eu/justice/news/consulting public/judgements/contributions/academics/max_planck_working_group_en.pdf; C.F. NordmEIER/J. SchichmanN, "Der Europäische Beschluss zur vorläufigen Kontenpfändung: Brennpunkte seines Erlasses und der Absicherung des Schuldners aus praktischer Perspektive", $R I W, 63,7,2017$, pp. 407-415;B. Nunner-Kraugtgasser, "Der geplante Rechtstackt zur europäischen Kontenpfändung”, en B. Hess (coord.) Die Anerkennung im Internationalen Zivilprozessrecht - Europäische Vollstreckungsrecht, Bielefeld, Gieseking, 2014, pp. 125 y ss;;J. RieBold, Die europäische kontopfändung, Tübingen, Mohr, 2014, pp. 390-426; L.SANDRINI, "Nuove prospettive per un più efficace cooperazione guidiziaria in material civile: il regolamento (UE) N. 655/2014, Riv. dir. Int. priv. proc., 2/2017,pp. 283-355;L.SANDrin, Tutela Cautelare in funzione di giudizi esteri, Cedam, Milán, 2012, pp. 100-172 y 281-398; D.Solomon, "Haftung, Sicheheitsleistung und Unertakings im Internationalen Vollstreckungsrecht", en B. Hess (coord.) Die Anerkennung im Internationalen Zivilprozessrecht - Europäische Vollstreckungsrecht, Bielefeld, Gieseking, 2014, pp. 173- 213;H. SCHUMACHER/B. KöllensPerger/M. TrenKer, Kommentar zur EU-Kontenpfändungsverordnung (EuKoPfVO), Wien, MANZ'sche Verlags- und Universitätsbuchhandlung, 2017; T. WeimanN/F. HeuKamp, "Die grenzüberschreitende vorläufige Kontenpfändung: gesetzliche Grundlagen und erste Einschätzung aus der Beratungspraxis", Monatsschrift für deutsches Recht, 71, 12, 2017, pp. 673-679.

${ }^{5}$ DOUE L 283/1, de 19 de octubre de 2016.

${ }^{6}$ A.L. Calvo Caravaca/J. Carrascosa González, "Medidas provisionales cautelares y Reglamento Bruselas I-bis", Rivista di diritto internazionale privato e processuale, $\mathrm{n}^{\circ}$ 1/2015, p. 55.F.J. GARCIMARTín AlFÉREZ, El régimen de las medidas cautelares en el comercio internacional, Mc. Graw Hill, Madrid, 1996, pp. 92-99. 
de 2012 relativo a la competencia judicial, el reconocimiento y la ejecución de resoluciones judiciales en materia civil y mercantil (en adelante el RBI-bis) ${ }^{7}$ y en particular a su art. $35^{8}$. Este artículo no instaura una serie medidas cautelares homogéneas para los Estados parte del Reglamento sino que remite al Derecho procesal del Estado miembro al que se le solicita la medida. Esto hace que sea necesario recurrir al Derecho procesal nacional para saber qué medidas cautelares se pueden ejercitar y cómo es su regulación. En determinados escenarios, cuando el tribunal que conoce del fondo del asunto no es al que se le solicita la medida cautelar, el acreedor debe informarse sobre ese derecho procesal extranjero diferente del Estado cuyos tribunales le han reconocido o le van a reconocer su derecho de crédito. Esto puede hacer que muchas deudas no lleguen nunca a cobrarse.

3) La dificultad para el acreedor de conocer el patrimonio del deudor ${ }^{9}$. El conocimiento del acreedor de los bienes del deudor es clave para una futura ejecución de una deuda. Sin embargo, no resulta sencillo averiguar el patrimonio del que dispone el deudor y menos cuando se trata de una deuda transfronteriza. Es una materia que a pesar de su relevancia no se encuentra armonizada. Esto da lugar a que cada Estado cuente con sus propios medios de averiguación del patrimonio del deudor. En el ordenamiento jurídico español, el deudor tiene el deber de colaborar en todo el proceso con la Administración de Justicia (art. 17.1 LOPJ). Este deber obliga a que sea transparente con su patrimonio. Con el fin de concretar este deber del deudor, el derecho procesal español establece una serie de medidas de averiguación patrimonial, las cuales son básicamente las siguientes: 1) el requerimiento de manifestación de bienes del ejecutado (art. 589 LEC); 2) la investigación judicial del patrimonio del ejecutado (art. 590 LEC ); 3) el deber de colaborar de terceros (art. 591 LEC) ${ }^{10}$.

Cuando los fondos del deudor se encuentran en el extranjero, ante la inexistencia de un instrumento legal internacional al efecto, la doctrina ha considerado que se debería realizar una interpretación extensiva de los instrumentos legales vigentes aunque no regulen específicamente los aspectos relativos a la averiguación patrimonial del deudor ${ }^{11}$. En particular se debería atender ad ex. al Reglamento (CE) $n^{o}$ 1206/2001 del Consejo, de 28 de mayo de 2001, relativo a la cooperación entre los órganos jurisdiccionales de los Estados miembros en el ámbito de la obtención de pruebas en materia civil o mercantil ${ }^{12}$.

Aunque no existe ningún instrumento legal internacional europeo en la materia, hay que recordar que el R. 655/2014 mediante el que se crea la OERC instaura en su art. 14 un mecanismo inexistente hasta la fecha. El citado art. 14 regula la vía que permite obtener información sobre las cuentas del deudor. Esta regulación implica un paso importante en la obtención de información sobre el patrimonio del deudor.

4) La facilidad para trasladar el dinero de unos países a otros. La reducción de costes de las transferencias bancarias entre países. Esa reducción de costes no es únicamente desde una perspectiva económica sino también técnica. Hoy día con las nuevas tecnologías sólo es necesario una conexión a internet para enviar el dinero a cualquier parte del mundo ${ }^{13}$.

\footnotetext{
${ }^{7}$ DOUE L 351/1, de 20 de diciembre de 2012.

${ }^{8}$ Sobre el régimen de tutela cautelar que se instaura a nivel europeo con el Reglamento Bruselas I bis Vid.ad ex. F.J. GarCIMARTín Alférez, "Provisional and protective measures under the Brussels I Recast", 16 YPIL, 2014/2015, pp.; C. Honorari, "Provisional Measures and the recast of Brussels I Regulation: a missed oportunity for a better ruling", Rivista di diritto internazionale privato e processuale, № 3/2012, pp 525-544; I. Pretelli, "Chapter 5. Provisional and Protective Measures in the European Civil Procedure of the Brussels I System”, en V. Lazic/S. Stui (eds.), Brussels I bis Regulation, Short Studies in Private International Law, 2016, pp. 97-117; L. SANDRIN, Tutela Cautelare in funzione di giudizi esteri, Cedam, Milán, 2012, pp. 100-172 y 281-398.

${ }_{9}$ B. Hess, Study $n^{0}$ JAI/A3/2002/02 on making more efficient the enforcement of judicial decisions within the European Union: Transarency of a Debtor's Assets, Attachment of Bank Accounts, Provisional Enforcement and Protective Measures, pp. 26 y ss. Disponible en http://www2.ipr.uni-heidelberg.de/studie/General\%20Report\%20Version\%20of\%2018\%20Feb\%202004. pdf (consultado el 14 de diciembre de 2019).

${ }^{10}$ M. Casado Abarquero, "La investigación del patrimonio del deudor ejecutado en el extranjero", AEDIPr, t. IX, 2009, p. 466.

${ }^{11}$ Ibidem, p. 471.

${ }^{12}$ DOCE 174, de 27 de junio de 2001.

${ }^{13}$ R. Miquel SAla, "La futura orden europea de retención de cuentas para simplificar el cobro transfronterizo de deudas en materia civil y mercantil”, $C D T$, vol. 4, nº 2, 2012, p. 218.
} 


\section{Pero ¿qué es realmente una Orden Europea de Retención de Cuentas?}

4. La OERC es una medida cautelar europea. Es una medida que coexiste con las de los derechos procesales nacionales de los Estados miembros, en ningún caso las elimina, sino que es planteada por el legislador europeo como una opción más entre las que podría contar el acreedor para asegurarse la ejecución de su deuda. El fin es retener los fondos del deudor, pero sin llegar a transferírselos al deudor. Como su propio nombre indica, la OERC es una "retención", un embargo preventivo, pero no una medida ejecutiva. Cinco rasgos sobre la OERC podrían destacarse con el fin de entender verdaderamente cómo concibe esta medida el R. 655/2014, estos son los siguientes ${ }^{14}$ :

1) Complementaria. La OERC presenta un carácter suplementario a cualquier otra orden de retención nacional que el acreedor haya solicitado u obtenido contra el mismo deudor (art. 16.4 R. 655/2014 $)^{15}$. La existencia de la OERC no deja inoperativos otros procedimientos de carácter nacional con efectos equivalentes a la orden europea ${ }^{16}$. El acreedor en el caso de haber solicitado previamente una orden nacional equivalente debe indicarlo en la solicitud de la orden europea. Éste debe indicar si dicha orden nacional se ha admitido o rechazado. Si se ha admitido debe señalar en qué términos, ya que ello condicionaría los fondos a retener por la OERC, no pudiendo exceder nunca del derecho de crédito reconocido. Esta obligación del acreedor de informar al órgano jurisdiccional sobre la existencia de otras medidas le acompaña durante todo el procedimiento, no sólo al solicitar la OERC. Si una vez admitida la orden europea hay pronunciamientos sobre la medida nacional, el acreedor debe comunicarlo al órgano jurisdiccional (art. 16.3 R. 655/2014).

2) No erga omnes. La OERC sólo puede ser utilizada por los acreedores que se encuentran domiciliados en un Estado parte del R. 655/2014. Del mismo modo, las cuentas bancarias sobre las que se puede llevar a cabo una retención deben encontrarse en el territorio de un Estado parte, bien pueden estar todas las cuentas en un mismo banco o en diferentes bancos dentro de un mismo Estado miembro o incluso diferentes cuentas en diferentes Estados miembros. Esta conexión exigida con la Unión Europea permite que el proceso para conceder la orden sea ágil.

3) Autónoma. La autonomía que presenta la OERC se puede apreciar en dos sentidos: a) la OERC cuenta con un procedimiento propio. El R. 655/2014 detalla todo el procedimiento necesario para su solicitud, obtención y ejecución. Además de sus efectos y las vías para su impugnación: b) la OERC es una medida que funciona de forma independiente y autónoma a otras medidas con efectos equivalentes. Es decir, su eficacia se consigue una vez que el banco efectúa la orden de retención. Si las cantidades retenidas no fueran las solicitadas inicialmente (el deudor no cuenta con fondos suficientes), el resto de bienes del deudor no se ven afectados. De este modo, se podría extraer también que la orden europea es una medida mediante la cual no se van a embargar bienes inmuebles.

Esta autonomía funcional no es compartida por el embargo preventivo (medida nacional equivalente a la OERC) que existe en el Derecho procesal español. Éste permite embargar otros bienes aparte de las cuentas corrientes cuando éstas no arrojan saldo suficiente para cubrir la orden de embargo (arts. 592 y 738 apartados 1 y 2 LEC).

4) No personal. La OERC es una medida cuyo objetivo son las cuentas del deudor, no su persona. Esto se traduce en que la admisión de la orden permitiría al deudor seguir disponiendo de su patrimonio en tanto en cuando no afecte a los fondos retenidos. Además, debido a este

${ }^{14}$ C. SenÉs Motilla, La orden Europea de Retención de Cuentas. Aplicación en Derecho español del Reglamento (UE) núm. 655/2014, de 15 de mayo de 2014, Thomson Reuters Aranzadi, Cizur Menor (Navarra), 2015, pp. 63 y ss.

${ }_{15}$ Para un mayor detalle vid. G. Cuniberti/S. Migliorini, The European Account Preservation Order Regulation. A commentary, Cambridge, 2018, pp. 197-220.

${ }^{16} \mathrm{M}^{\mathrm{a}}$. Ángeles Rodríguez Vázquez, "La orden europea de retención de cuentas", Revista de Derecho Patrimonial, 38, 2015 , p. 148. 
carácter, es posible que la retención pueda afectar a fondos que no sólo pertenecen al deudor. Esto podría tener lugar cuando el deudor comparte titularidad en una cuenta con otra persona o un tercero aparece como titular en nombre del deudor.

\section{Hechos litigiosos de la STJUE de 7 de noviembre de 2019}

5. Un acreedor en base a un contrato de promesa de venta celebrado el 20 de octubre de 2017 acude a tribunales búlgaros, en concreto al Tribunal de Primera Instancia de Sofía (Sofyski rayonen sad). El fin es reclamar el pago de un derecho de crédito contra determinados deudores obligados solidariamente. Este requerimiento de pago se sustenta en base al art. 410 del GPK (grazhdanski protsesualen kodeks), el código de procedimiento civil búlgaro ${ }^{17}$.

6. El 5 de abril de 2018, el Tribunal de Primera Instancia búlgaro dicta un requerimiento de pago contra esos deudores. Sin embargo, dichas notificaciones fueron devueltas siendo imposible notificar en tiempo y forma a los deudores ${ }^{18}$.

7. Posteriormente, el 2 de agosto de 2018, el Tribunal de Primera Instancia búlgaro dicta una providencia mediante la cual indica al demandante que podía ejercitar una acción declarativa de su derecho de crédito frente a los deudores en virtud del art. 415, apartado 1, punto 2, del GPK. Estudiada la situación, el demandante decide solicitar a ese mismo tribunal una OERC. El acreedor alega que tiene cocimiento de que los deudores ahora se encuentran en Suecia y no en Bulgaria ${ }^{19}$.

Ante la solicitud del acreedor de una OERC, el Tribunal de Primera Instancia comunica la solicitud al Presidente de la sección segunda de lo Civil de ese mismo tribunal con el fin de que se inste un procedimiento separado para tramitar la OERC. Sin embargo, el presidente devuelve el asunto al Tribunal de Primera Instancia para que lo resuelva, ya que no procedía incoar un procedimiento por separado. El razonamiento jurídico de esta devolución es que el Tribunal de Primera Instancia dictó un requerimiento de pago el 5 de abril de 2018 y el mismo debería entenderse como un $<<$ documento público con fuerza ejecutiva>> en el sentido del art. 4, apartado 10 del R. 655/2010.

8. El Tribunal de Primera Instancia búlgaro no comparte este criterio. Entiende que el requerimiento de pago dictado carece de fuerza ejecutiva, ya que es revocable y el deudor puede oponerse al $\mathrm{mismo}^{20}$. En este caso, uno de los motivos por los que no ha podido existir oposición de los deudores es porque no se les pudo localizar. Además, el Tribunal de Primera Instancia también argumenta que el acreedor debe demostrar que ha ejercitado la acción dentro del plazo que determina el Código de procedimiento búlgaro, requisito que no ha sido cumplido. En la misma línea, el Tribunal de Primera Instancia argumenta que en el procedimiento de requerimiento de pago en atención al Código de procedimiento búlgaro, el juez no está sujeto a plazo alguno para resolver salvo lo dispuesto por el Derecho nacional, plazo que se suspende durante las vacaciones judiciales. Sin embargo, el juez al que se le solicita una OERC debe resolver en un plazo concreto, el que señala el art. 18 del R. 655/201421.

Expuestos los hechos, el Tribunal de Primera Instancia búlgaro le pregunta al TJUE básicamente lo siguiente ${ }^{22}$ :

1) Si a la luz del Código de procedimiento búlgaro, en concreto en base al art 410 del GPK, un requerimiento de pago puede ser considerado "un documento público con fuerza ejecutiva" en el sentido del art. 4 punto 10 del R. 655/2014.

\footnotetext{
${ }_{17}$ STJUE 7 de noviembre 2019, K.H.K contra B.A.C. Y E.E.K, C-555/18, ECLI:EU:C:2019:937, apartado 19.

${ }_{18}$ Ibidem, apartado 20.

19 Idem, apartados 22 y 23.

${ }^{20}$ Sobre este particular vid. las Conclusiones del Abogado general Sr. MaCiEJ SzPunAr presentadas el 29 de julio de 2019, ECLI: EU:C:2019:652, apartados 37 a 40.

${ }^{21}$ STJUE 7 de noviembre 2019, K.H.K contra B.A.C. Y E.E.K, C-555/18, ECLI:EU:C:2019:937. apartado 26.

${ }^{22}$ Ibidem, apartado 27.
} 
2) Si un requerimiento de pago puede calificarse como un procedimiento sobre el fondo del asunto en el sentido del art. 5 letra $^{\circ}$ del R. 655/2014.

3) Si el término <<circunstancias excepcionales $>>$ al que se refiere el art. 45 del R. 655/2014 podría incluir también vacaciones y que por lo tanto la inclusión de ese período pudiera justificar la suspensión del plazo de 10 días que el art. 18 del R. 655/2014 establece como límite para que un juez resuelva sobre la solicitud de una OERC.

\section{Problemas jurídicos que suscita esta resolución}

1. La importancia de si el acreedor tiene reconocido o no su crédito mediante una resolución judicial, transacción judicial o documento público con fuerza ejecutiva

\section{A) Aproximación al problema}

9. El Tribunal búlgaro de Primera instancia pregunta al TJUE si un requerimiento de pago dictado en base al Derecho procesal búlgaro se puede considerar un documento público con fuerza ejecutiva en atención al art. 4 apartado 10 del R. 655/2010. Esta cuestión puede parecer a simple vista que no tiene demasiada importancia, sin embargo, todo lo contrario. Cuando un acreedor se plantea solicitar una OERC, el primer aspecto que debe precisar es si cuenta o no con una sentencia, transacción judicial documento público que reconozca su crédito. Sin embargo, del tenor literal del art. 4 apartados 8 a 10 no se puede llegar a precisar de forma expresa si cuando el R.655/2014 define "resolución judicial", "transacción judicial" o "documento público" se refiere a que sean títulos que ya tienen carácter ejecutivo. Esta precisión es importante porque en muchas disposiciones a lo largo del R. 655/2014 se diferencia entre dos escenarios:

1) El acreedor todavía no cuenta con una resolución judicial, transacción judicial o documento público con fuerza ejecutiva.

2) El acreedor sí cuenta con una resolución judicial, transacción judicial o documento público con fuerza ejecutiva.

En particular, que el acreedor cuando solicita la OERC cuente o no con un reconocimiento judicial de su crédito es relevante para aspectos como:

1) La determinación de la competencia judicial internacional (art. 6 R. 655/2014);

2) La información a la que el acreedor va a poder acceder sobre las cuentas bancarias del deudor (art. 14 R. 655/2014);

3) La necesidad de prestar caución (art. 12 R. 655/2012).

4) El plazo del que dispone el juez para resolver la solicitud sobre la OERC (art. 18 R. 655/2014).

10. En relación a la competencia de los tribunales para dictar una OERC, es necesario tener presente el art. 5 R. 655/2014. Este precepto permite que el acreedor pueda solicitar una OERC en diferentes momentos procesales. Bien cuando el acreedor todavía no tiene una resolución, transacción o documento público con fuerza ejecutiva sobre el fondo o bien cuando el acreedor ya dispone de una resolución judicial, transacción judicial o documento público con fuerza ejecutiva. Esto permite que el acreedor pueda solicitar la OERC:

1) Antes de incoar un procedimiento judicial mediante el cual se reclama una deuda.

2) Cuando se interpone la demanda reclamando la deuda.

3) En el transcurso del procedimiento.

4) Una vez obtenida la resolución judicial, la transacción judicial o el documento público con fuerza ejecutiva que obliga al deudor al pago de la deuda. 
Esta amplia posibilidad de que el acreedor pueda interponer la OERC en diferentes momentos procesales tiene su influencia en la competencia judicial internacional. Así, el art. 6 R.655/2014 en atención al momento procesal en el que se presente la OERC otorga competencia judicial a unos tribunales u a otros. Así, si el acreedor no tiene su crédito reconocido mediante una resolución judicial, una transacción judicial o como se cuestiona en este caso en base a un documento público con fuerza ejecutiva, el juez competente para dictar la OERC será el que ostente competencia para conocer del fondo del asunto (arts. 6.1 R. 655/2014).

Sin embargo, si el acreedor sí tiene su crédito reconocido mediante una sentencia judicial o una transacción judicial el juez competente para dictar la orden será el que ha dictado la resolución o el que haya aprobado la transacción judicial (art. 6.3 R. 655/2014). En el caso de que el crédito se reconozca en un documento público con fuerza ejecutiva, será competentes los órganos designados a tal fin en el Estado miembro en el que dicho documento se haya formalizado (art. 6.4 R. 655/2014).

11. Respecto de la información que el acreedor puede obtener sobre las cuentas del deudor, el art. 14.1 R. 655/2014 permite que el acreedor pueda obtener información sobre las cuentas del deudor sólo en el caso de que cuente con una sentencia judicial, una transacción judicial o un documento público con fuerza ejecutiva. Esa petición de información puede concederse por la autoridad judicial aunque la sentencia judicial, la transacción o el documento público aún no tengan carácter ejecutivo. Sin embargo, en este caso deberá justificar el acreedor dos extremos: 1) que el importe retenido es sustancial a las circunstancias del caso; 2) que existe urgencia en obtener la información porque hay riesgo de que no se pueda llegar a cobrar la deuda. Por lo tanto, se puede apreciar que si el acreedor aún no ha incoado un proceso sobre el fondo o habiéndolo incoado todavía no ha finalizado, el órgano jurisdiccional no va informar al acreedor sobre las cuentas del deudor. Esto obedece a diferentes motivos, uno de ellos es que se trata de información sensible, información personal sobre el deudor, y si no se tiene un derecho de crédito reconocido judicialmente, el legislador europeo ha querido ser cauto al respecto con el fin de salvaguardar los intereses del deudor.

12. Siguiendo con la importancia de contar con un título que reconozca el crédito, esto también influye en los plazos en los que el juez debe resolver la orden y también sobre la exigencia de caución. En el caso que el acreedor tenga ya reconocido su crédito, el plazo mediante el cual debe resolver el juez es de 5 días hábiles desde que se haya presentado la orden. Sin embargo, en el caso de que no cuente con una resolución judicial, transacción judicial o documento público con fuerza ejecutiva el plazo se amplia hasta 10 días. Esto es así porque si el acreedor no cuenta con el crédito reconocido judicialmente, el juez debe disponer de más tiempo para comprobar que efectivamente tal derecho de crédito se ostenta (fumus boni iuris).

Lo mismo sucede con la caución, como regla general si el acreedor no cuenta con su derecho de crédito reconocido mediante una sentencia, una transacción judicial o un documento público con fuerza ejecutiva va a tener que prestar caución (art. 12.1 R. 655/2014). Sin embargo, si el acreedor ya tiene reconocido su derecho de crédito lo habitual será no tener que prestarla. Esta regla general presenta excepciones. De este modo, la caución no será requerida aunque el acreedor no tenga reconocido su crédito cuando pruebe que no cuenta con medios económicos para hacer frente a la caución o en el caso de que la deuda sea de escasa entidad y el juez no lo estime necesario. A sensu contrario, generalmente sí será requerida la caución aunque el acreedor ya cuente con un título que le reconoce su crédito pero aún no tenga carácter ejecutivo o sólo lo sea de forma provisional (considerando 18). En definitiva, la caución es una prerrogativa a favor del deudor ${ }^{23}$. Es una forma de equilibrar las obligaciones y derechos entre deudor y acreedor. Esto es así porque puede realizar una doble función $\left.{ }^{24}: 1\right)$ permite disuadir las demandas de crédito infundadas;2) hace frente a los daños y perjuicios que la orden puede causar en el patrimonio del deudor en el caso de que el derecho de crédito sea desestimado ${ }^{25}$.

\footnotetext{
${ }^{23}$ G. Cuniberti/S. Migliorini, The European Account ..., p. 156.

${ }^{24}$ P. JimÉnez Blanco,'La orden europea de retención de cuentas: avances y limitaciones”, AEDIPriv, t-XIV-XV,2014-2015, p. 254.

${ }^{25}$ Considerando 18 R. 655/2014. En la doctrina sobre este particular, vid. C. SenÉs Motilla, La orden europea ..., pp. 105-106.
} 


\section{B) La solución del TJUE}

13. De este modo, como se puede comprobar reviste importancia el hecho de si el acreedor cuenta o no con una resolución judicial, transacción judicial o documento público con fuerza ejecutiva, ya que el procedimiento sobre la tramitación de la orden sufre variaciones. En el caso que analizamos se le pedía al TJUE que precisase si un requerimiento de pago podía ser considerado un documento público con fuerza ejecutiva en el sentido del art. 4 apartado 10 R. 655/2010. Por lo tanto, el aspecto clave a precisar es si las definiciones del art. 4 apartados 8 a 10 de "resolución judicial", "transacción judicial" y "documento público con fuerza ejecutiva" se deben entender de forma declarativa o ejecutiva.

El TJUE en la sentencia objeto de comentario precisa de forma acertada que del término "resolución judicial ", "transacción judicial" y "documento público con fuerza ejecutiva" como se define en el art. 4 en sus apartados 8 a 10 no determina expresamente si deben entenderse como ejecutivos ${ }^{26}$. Por lo tanto, para el TJUE no se puede considerar de la literalidad de los preceptos que "resolución judicial", "transacción judicial" y "documento público con fuerza ejecutiva" tengan que ostentar necesariamente carácter ejecutivo en atención al art. 4 R. 655/201427.

Sin embargo, de la interpretación de otros preceptos importantes del Reglamento, como son los arts. 7 (donde se establecen los requisitos para que se pueda conceder la OERC), el art. 14 (información que se le puede otorgar al acreedor sobre las cuentas del deudor) o el art. 12 (necesidad de prestar caución) al igual que de la interpretación basada en los trabajos preparatorios del Reglamento además de tener siempre presente que debe existir un equilibrio entre los derechos del acreedor y del deudor en el procedimiento sobre la OERC se debe entender que cuando el apartado 10 del art. 4 R.655/2014 se refiere a "documento público con fuerza ejecutiva" debe entenderse que se trate de un título con carácter ejecutivo. Lo mismo sucedería con los conceptos de "resolución judicial" y "transacción judicial" en relación a los apartados 8 y 9 del art. 4 R. 655/2014.

Por lo tanto, una vez precisado cómo se deben entender estos conceptos, surge un segundo problema a resolver que plantea este asunto. Este sería el siguiente: en el caso de que el acreedor cuente con un título que le reconoce su derecho de crédito, en base a qué derecho se debe considerar que ese título ostenta carácter ejecutivo. Es decir, si es el Derecho del país donde se solicita y dicta la OERC o es el Derecho del país que la ejecuta.

El TJUE basándose de nuevo en los trabajos preparatorios sobre el R. 655/2014 considera que el título que reconoce el derecho de crédito debe ser considerado ejecutivo en el Estado de origen ${ }^{28}$. La misma visión sustentó el Abogado General que emitió sus conclusiones en este asunto ${ }^{29}$. De este modo, resulta indiferente el status que el Estado de ejecución pueda otorgar a ese título crediticio. Lo importante es lo que establezca el Estado de origen. Así, se deberá atender al Derecho procesal búlgaro para saber si un requerimiento de pago es ejecutivo o no lo es. En atención a dicho ordenamiento, un requerimiento de pago como el que ha dictado el Tribunal de Primera Instancia de Sofía no tiene carácter ejecutivo. El TJUE precisa que al carecer de ese carácter ejecutivo no se puede entender que ese requerimiento de pago pueda encajar dentro del concepto que el R. 655/2014 recoge sobre documento público con fuerza ejecutiva en su art. 4 apartado $10^{30}$.

En definitiva, la respuesta del TJUE es que si un requerimiento de pago dictado conforme al Código procesal búlgaro como el que se ha dictado en el procedimiento principal que no tiene carácter ejecutivo para el citado Derecho no puede considerarse un documento público con fuerza ejecutiva en atención al art. 4 punto 10. Por lo tanto, el tribunal que ostentará competencia judicial internacional para dictar en este caso concreto una OERC será el tribunal que ostente competencia judicial internacional para conocer del fondo del asunto.

\footnotetext{
${ }^{26}$ STJUE 7 de noviembre 2019, K.H.K contra B.A.C. Y E.E.K, C-555/18, ECLI:EU:C:2019:937, apartado 39. 27

${ }^{28}$ STJUE 7 de noviembre 2019, K.H.K contra B.A.C. Y E.E.K, C-555/18, ECLI:EU:C:2019:937, apartado 44.

${ }^{29}$ Conclusiones del Abogado general Sr. MACiej SzPunar presentadas el 29 de julio de 2019, ECLI: EU:C:2019:652, apartado 70 .

${ }^{30}$ STJUE 7 de noviembre 2019, K.H.K contra B.A.C. Y E.E.K, C-555/18, ECLI:EU:C:2019:937, apartado 45.
} 


\section{La amplitud del concepto "procedimiento en cuanto al fondo" del art. 5 letra a R. 655/2014}

14. Como ya analizamos anteriormente, el art. 5 R. 655/2014 brinda al acreedor la oportunidad de poder solicitar la OERC no sólo cuando ya cuenta con una resolución judicial que le reconoce el derecho de crédito sino mucho antes. Incluso cuando todavía ni si quiera ha iniciado una acción judicial para reclamar la deuda. Es decir, un procedimiento en cuanto al fondo.

15. En el caso objeto de análisis, el Tribunal Búlgaro pregunta al TJUE si un requerimiento de pago en atención al art. 410 del Código Procesal búlgaro puede considerarse un procedimiento en cuanto al fondo en el sentido del art. 5 letra R. 655/2014. El Tribunal de Justicia interpreta el término $<<$ procedimiento en cuanto al fondo $>>$ de forma amplia en atención al considerando 13 del mismo Reglamento. Este considerando precisa que se debe entender "cualquier procedimiento cuyo objetivo sea obtener un título ejecutivo sobre la deuda subyacente, incluidos, por ejemplo, los procedimientos sobre medidas provisionales relativos a órdenes de pago". Por lo tanto, para el TJUE un requerimiento de pago conforme al art. 410 del Código procesal búlgaro puede considerarse un procedimiento en cuanto al fondo.

16. El objetivo de esta amplia definición es que a pesar de las diferencias que pueden existir entre los derechos procesales para reclamar y hacer ejecutiva una deuda, el legislador europeo no quería que esas diferencias supusieran un obstáculo para solicitar la OERC. De este modo, es indiferente que la acción mediante la que se reclama la deuda se realice de forma principal o reconvencional o que sea ejercitada a título principal o de forma acumulada ${ }^{31}$. Por lo tanto, no se consideraría como $<<$ procedimiento en cuanto al fondo $>>$ conforme al art. 5 letra a R. 655/2014 las diligencias preliminares. Es decir, todas esas actuaciones judiciales que tienen como objetivo la aclaración de cuestiones necesarias para el ejercicio de la acción de condena. Ad ex, extremos relativos a la capacidad, representación o legitimación del deudor ${ }^{32}$. Sin embargo, cualquier otro procedimiento cuyo fin sea la obtención de un reconocimiento de la deuda dirigido contra el deudor será considerado un $<<$ procedimiento en cuanto al fondo $>>$.

17. La consecuencia de que se considere un procedimiento en cuanto al fondo el requerimiento de pago realizado conforme al art. 410 del Código de procedimiento búlgaro es que la solicitud y posterior tramitación de la OERC se debe realizar ante ese tribunal. No es necesario un procedimiento separado como entendía el Tribunal de Primera Instancia de Sofía ${ }^{33}$. Es una cuestión que está íntimamente relacionada con la competencia judicial internacional. Cuando el acreedor carece de un título ejecutivo que le reconoce su crédito, el tribunal "mejor situado" para dictar la OERC es el tribunal que va a conocer o ya conoce sobre el fondo del asunto. En definitiva, es el que mejor va a poder determinar si procede o no conceder la orden para proteger la deuda transfronteriza. Ese tribunal que conoce del fondo es el que mejor puede apreciar si concurren los dos requisitos básicos para conceder la OERC el periculum in mora y el fumus boni iuris (art. 7 R. 655/2014), ya que no hay que olvidar que la concesión de la orden no es automática.

\section{En torno a qué engloba el término "circunstancias excepcionales" del art. 45 R. 655/2014}

18. El tribunal de Primera Instancia Búlgaro le pregunta al TJUE en la tercera cuestión que le formula si dentro las "circunstancias excepcionales" a las que se refiere el art. 45 pueden incluirse también las vacaciones judiciales.

19. El legislador europeo en diferentes artículos a lo largo del $R$ 655/2014 va fijando plazos con el fin de que la tramitación y ejecución de la orden sea ágil y cumpla su función. De nada serviría una medida como la OERC si el juez tarda en resolver sobre su procedencia meses. Así, como ya hemos

\footnotetext{
${ }^{31}$ C. Senés Motilla, La orden Europea ..., p. 91.

${ }^{32}$ Ibidem, p. 91.

${ }^{33}$ STJUE 7 de noviembre 2019, K.H.K contra B.A.C. Y E.E.K, C-555/18, ECLI:EU:C:2019:937, apartados 50 y 51.
} 
señalado el plazo para resolver sobre la orden es de 5 día si el acreedor ya cuenta con una resolución judicial, transacción judicial o documento público con fuerza ejecutiva que le reconozca su crédito. Este plazo podría ampliarse, pero sólo de forma excepcional cuando concurran determinadas circunstancias. Sobre que circunstancias podrían tener ese carácter "excepcional" se refiere el considerando 37. Este considerando se refiere a asuntos difíciles, complejos, bien desde un punto de vista jurídico o fáctico. Sin embargo, es impreciso y no sugiere una interpretación estricta ${ }^{34}$.

20. Sobre este particular, el TJUE resuelve que las vacaciones judiciales no pueden entenderse como una circunstancia excepcional a efectos del art. 45 R. 655/2014 ${ }^{35}$. Esta interpretación es totalmente acorde con el propio tenor literal del art. 45. El precepto determinar que en el caso de que no se puedan cumplir los plazos de todos los artículos del R. 655/2014 que señala, el órgano jurisdiccional o autoridad correspondiente debe resolver lo antes posible.

21. Aunque no guarde relación con la cuestión prejudicial, este art. 45 no deja de ser una vía de escape del legislador europeo con el fin de evitar imponer plazos estrictos a las autoridades de los Estados miembros. Este art. 45 permite que la autoridad nacional que resuelve sobre la orden pueda alegar que no ha podido resolver la solicitud de la OERC en los plazos marcados en el art. 18 porque el caso simplemente era complejo. En realidad, el art. 45 es una forma de evitar imponer sanciones a los Estados miembros por no cumplir el derecho europeo. A nuestro juicio, quizás un error porque puede dar lugar a dilaciones que lo único que hacen es perjudicar el funcionamiento de la OERC ${ }^{36}$.

\section{Reflexiones finales}

22. Esta primera sentencia del TJUE es una buena excusa para poder profundizar más en el estudio del R. 655/2014. Este Reglamento que crea la primera medida cautelar europea es un instrumento importante para acabar con las dificultades que entraña el cobro de un crédito transfronterizo. Esta sentencia muestra como la aplicación del R. 655/2014 no resulta fácil para las tribunales nacionales. Esto es así porque aunque pueden existir conceptos dentro del R. 655/2014 que pueden ser poco claros o imprecisos, esta sentencia muestra como los mayores problemas se derivan de engarzar la aplicación del R. 655/2014 con el Derecho procesal nacional. En este caso era el búlgaro, pero intuimos que serán muchas las cuestiones prejudiciales que se plateen por los tribunales nacionales sobre el funcionamiento de la OERC al TJUE.

23. En particular, los cuatro aspectos suscitados en la sentencia objeto de comentario, pueden quedar resumidos en: 1) se debe entender implícitamente (literalmente no se señala) que cuando el art. 4 en sus apartados 8 a 10 define "resolución judicial", "transacción judicial" o "documento público con fuerza ejecutiva" son títulos con carácter ejecutivo; 2) qué Derecho (si el del Estado de origen o el de ejecución) determina el carácter ejecutivo de una documento público con fuerza ejecutiva (art. 4 apartado 10 R. 655/2010); 3) qué procesos caen dentro de la definición "procedimiento en cuanto al fondo"(art. 5 letra a R. 655/2014); 4) qué circunstancias son consideradas excepcionales para poder aplazar la resolución(art. 45 R. 655/2014).

24. Las respuestas que otorga el TJUE a estas cuestiones hace que se considere que un requerimiento de pago como el suscitado en el asunto principal no se considere un documento público con fuerza ejecutiva. El TJUE interpreta que el art. 4 apartado 10 debe entenderse como título ejecutivo. Pero dicha ejecutividad se debe derivar del Estado de origen, el acreedor búlgaro no cuenta con un título ejecutivo que le reconozca su crédito, por lo tanto va a tener que litigar para obtenerlo. De hecho, para el TJUE ya lo está haciendo, ese requerimiento de pago que se llevó a cabo ante el Tribunal de Primera

\footnotetext{
${ }^{34}$ G. Cuniberti/S. Migliorini, The European Account..., p. 327.

${ }^{35}$ STJUE 7 de noviembre 2019, K.H.K contra B.A.C. Y E.E.K, C-555/18, ECLI:EU:C:2019:937, apartados 55 y 56.

${ }^{36}$ Sobre este particular vid. G. Cuniberti/S. Migliorini, The European Account..., p. 327.
} 
Instancia de Sofía puede considerarse como un procedimiento en cuanto al fondo. Por lo tanto, a priori el tribunal competente para dictar la procedencia de la OERC va a ser ese mismo tribunal que dictó el requerimiento de pago. Además, el plazo para resolver sobre la orden es el que determina el art. 18, el R. $655 / 2014$ no tiene nada que decir en cuanto a los plazos para resolver el fondo del asunto. Esos plazos del art. 18 sólo pueden ser ampliados cuando concurran circunstancias excepcionales como señala el art. 45. Según el TJUE, dentro de las mismas no se puede incluir el período de vacaciones judiciales. 